\title{
6 Organization and Funding of Digitization in the Visegrád Countries
}

\section{Introduction}

“Europe's cultural heritage, both tangible and intangible, is our common wealth - our inheritance from previous generations of Europeans and our legacy for those to come. It is an irreplaceable repository of knowledge and a valuable resource for economic growth, employment and social cohesion. It enriches the individual lives of hundreds of millions of people, is a source of inspiration for thinkers and artists, and a driver for our cultural and creative industries. Our cultural heritage and the way we preserve and valorise it is a major factor in defining Europe's place in the world and its attractiveness as a place to live, work, and visit.” (European Commission 2014)

These few sentences from the European Commission's Communication from 2014 mirrors the European Commission's view on our common cultural heritage that needs to be digitally reproduced, provided via digital services and preserved for future generations. The charge is laid to cultural institutions of the European Union member states.

Digital technologies mean new opportunities for museums, archives and libraries to fulfil their historic mission: providing people with information and cultural heritage content and giving access to the published knowledge. Digital technologies have also changed the way of the consumption of cultural content and moreover breathed new life into artefacts. The European Union intends to take a very significant role in developing common ways of collecting, processing and protecting the cultural assets related to the European nations' heritage. Europe has historically one of the oldest, most diverse and richest heritages in the world and therefore all European countries, the European Commission, the European Union member states and their institutions have important responsibility for ensuring the preservation of cultural content.

In this article I will analyze how Visegrád countries implemented the European Commission's recommendations on digitization and digital preservation related to organization and funding issues into their cultural policies.

The Visegrád Four (V4) term refers to four Central and Eastern European countries, Czech Republic, Hungary, Poland and Slovakia, which - based on their common historical, economic and cultural background - form an alliance within the European Union. The Visegrád name is derived from the 1335 Congress of Visegrád 
where the Bohemian, Hungarian and Polish kings (John I of Bohemia, Charles Robert of Hungary and Casimir III of Poland) agreed on the creation of new commercial routes in the Castle of Visegrád in Hungary. After the fall of Communism on 15 February, 1991, three heads of states from Czechoslovakia, Hungary and Poland signed an agreement on cooperation in different areas. After the dissolution of Czechoslovakia, the former Visegrád Triangle became the Visegrád Four.

The socio-political development of the four countries in the twentieth century is very similar. The life behind the iron curtain, the change of the communist regimes, the transition period and finally joining the European Union hand in hand on 1 May, 2004 all represent the countries' common destiny. Now the alliance has a growing importance both in political and economical terms within the European Union. The states in many respects make up an opposition with the European Union. This opposition may also be linked to former cultural experiences if we take the approach of migration crisis as an example. Tracing back the history of V4 cooperation to 1335 we can find the antitype of this opposition to the Western neighbors as the kings met in Visegrád to find new commercial routes to bypass the city of Vienna.

Though after the 1989 political turn the V4 countries lagged behind in economic terms, very innovative solutions have been elaborated in the field of promotion of digital culture. Hungary in particular had strong traditions in the field of digitization before the country's EU membership. We can mention a great pioneer within computer science, John von Neumann, whose name referred to an early example of digital libraries in the end of 1990. One of the Neumann digital library and multimedia center's innovations was that it offered unlimited access to the masterpieces of contemporary national literature based on mutually profitable agreements between authors or copyright holders and the Hungarian government. The institution beat the path to online services of digitally reproduced copyright protected material.

The V4 represents a continuously strengthening group of countries with common values, a strong identity that is occasionally expressed opposite to the mainstream European Union opinions and ideas. Analyzing the cultural heritage field, many questions have emerged. Is this opposition present in the implementation of digitization policies too? How is the common historical, economic, social background reflected in the implementation of EU recommendations in the field of cultural heritage? How does the common characteristics of V4 countries appear in the field of digitization policies?

The paper has two main objectives.

1. Firstly, I shortly present the European Commission's recommendations (European Commission 2011) related to organization and funding that aims to 
supports the member states in developing and implementing national policies related to digitization and digital preservation in the cultural field.

2. Based on the latest national progress reports that the countries are obliged to submit to the European Commission I will analyze how Visegrád countries (Czech Republic, Hungary, Poland and Slovakia) implemented the European Commission's recommendations related to organization and funding of digitization of cultural material and digital preservation into their national policies.

Do we find reflections of the V4 countries' common platform and common background in the way they approach the digitization of the cultural heritage or are these processes first and foremost directed by technological groups of experts more loosely coupled to the common platform and history of the V4 countries?

\section{Digitization Policies}

The Digital Single Market Strategy is a high-level policy framework launched by the European Commission in 2015. It covers several policy actions, coordination and funding mechanisms that support - among others - the member states' cultural policies in the fields of digitization, online accessibility and digital preservation of cultural material. The strategy is based on the development of three key pillars (access, environment and economy/society). Digital developments from business to culture fall under this common framework shaped by the DSM strategy (European Commission 2015). Presently, this strategy defines the framework of the digitization of cultural heritage in the EU.

Three policy levels can be identified.

1. European Commission;

2. European Union member states;

3. Cultural Heritage Institutions of EU member states.

Between the different policy levels several connections, links can be found.

\section{European Commission}

Within the European Commission, the Directorate General for Communications Networks, Content and Technology is responsible for the issues related to digital cultural heritage. Several actions and activities have been made to exchange knowledge and to harmonize digitization policies on a European level. The fol- 
lowing three areas supervised by this directorate have key importance in shaping of the European Union cultural policies.

1. One important activity is the operation of the Expert Group on Digital Cultural Heritage and Europeana for the member states, which primarily aims to function as a forum for knowledge exchange (European Commission 2017). Its predecessor was the Member States Expert Group (MSEG) on Digitisation and Digital Preservation which was established with the aims of monitoring progress of the implementation of European Union recommendations and exchanging information and good practices of member states' policies and strategies on the digitization and online accessibility of cultural material and digital preservation (European Commission 2015).

2. Another important policy action was the issue of a recommendation that provides proposals for organization and funding of digitization activities in the member states, harmonizing legal regulations (digitization of public domain and in-copyright material) on a European level, which contains suggestions related to the contribution to Europeana and recommendations regarding digital preservation of cultural content (European Commission 2011). This recommendation changed a former one that was published in 2006 (European Commission 2006).

3. The third important policy area is the Europeana that represents the political vision on the presentation of the European cultural heritage and at the same time is a useful tool for retrieving cultural heritage objects through borders and sectors. Europeana was initiated by six heads of states (France, Germany, Hungary, Italy, Poland and Spain), led by Jacques Chirac president of France in 2005 who wrote a letter to Jose Manuel Barroso in which they proposed the launch of a common digital library of Europe that would virtually present Europe's rich cultural heritage; it started on 20 November, 2008 (European Commission 2008).

More actions could also be mentioned, but the above mentioned three points represent some very tangible and visible areas.

\section{European Union Member States}

The European Commission gives member states a free hand in how to implement the different paragraphs of the recommendation into practice, but expects each to submit a progress report in every second year in which the national governments describe their activities related to the recommendations. The national progress reports are available on the European Commission's portal and make it possible 
to reveal the various approaches that the different member states follow in cultural policies (European Commission 2017). Though the EU recommendation is not binding, every member state follows or at least takes this into account on various levels during policy actions.

\section{Cultural Heritage Institutions of Member States}

The cultural heritage institutions also define their own policies following the requirements of national governments' legislation. The organizations often refer directly to EU recommendations and policies and the above mentioned DCHE expert group also partly consists of representatives who are working in the cultural heritage institutions that suggests that a direct link between EU and institutional level policies also exists. On the other side, another chapter of this book reveals that although goals and policies are formulated at governmental or a higher level, those goals and policies are not implemented by the institutions (Stokstad, this volume).

\section{Method}

The paper is based on document analysis. The main source for policy documents is the portal of the European Commission's Directorate General for Communications Networks, Content and Technology where the above-mentioned recommendation (European Commission 2011) and every current policy document are available.

Former reports can also be found, but I only focused on the last submitted ones that apply to the 2015-2017 period. Every report is based on the same form that contains open and closed-ended questions. Within the first paragraph (Organization and funding) the respondent has to describe the present system and organization of digitization of cultural material. The reports contain references to past actions also, to make the current situation understandable. Therefore, the analysis of former reports would not add more value to this paper.

The organization and funding part - following the structure of the recommendation - contains the following themes:

1. Progress on planning and monitoring the digitization of cultural material
a) Planning digitization
b) Monitoring digitization

2. Progress on partnerships between cultural institutions and private sector

3. Progress on making use of Structural Funds

4. Progress on ways to optimize the use of digitization capacity and achieve economies of scale 
The European Commission's Directorate General for Communications Networks, Content and Technology makes consolidated reports every second year where they summarize the main conclusions derived from the member states' documents (European Commission 2018). I used this consolidated report as well where it provided additional contextual information.

Altogether, five documents were analyzed: firstly, the Commission Recommendation of 27.10.2011 on the digitization and online accessibility of cultural material and digital preservation (European Commission 2011) and then the latest 2015-2017 progress reports on the implementation of the recommendation from the four countries (Czech Republic, Hungary, Poland and Slovakia).

\section{Digitization Recommendations of the European Commission on Organization and Funding}

Recommendations of the European Commission to member states related to strategic approaches are listed under the "Digitisation: organisation and funding" chapter of the document as follows:

1. further develop their planning and monitoring of the digitisation of books, journals, newspapers, photographs, museum objects, archival documents, sound and audiovisual material, monuments and archaeological sites (hereinafter 'cultural material') by:

a) setting clear quantitative targets for the digitisation of cultural material, in line with the overall targets mentioned under point 7 , indicating the expected increase in digitised material which could form part of Europeana, and the budgets allocated by public authorities;

b) creating overviews of digitised cultural material and contributing to collaborative efforts to establish an overview at European level with comparable figures;

2. encourage partnerships between cultural institutions and the private sector in order to create new ways of funding digitisation of cultural material and to stimulate innovative uses of the material, while ensuring that public private partnerships for digitisation are fair and balanced, and in line with the conditions indicated in the Annex;

3. make use of the EU's Structural Funds, where possible, to co-finance digitisation activities in the framework of regional innovation strategies for smart specialisation;

4. consider ways to optimise the use of digitisation capacity and achieve economies of scale, which may imply the pooling of digitisation efforts by cultural institutions and crossborder collaboration, building on competence centers for digitisation in Europe. (European Commission 2011)

The setting up of quantitative targets is a clear message, though in case we expect comparable figures (see point “ $b$ ”) across Europe, this recommendation requires a two-sided mechanism in which national and joint European efforts should also be made. The "overall targets mentioned under point 7 " emphasize the importance of 
reuse of cultural content for commercial and non-commercial purposes to exploit the huge potential that digitization offers regarding the revitalization of cultural artefacts. The setting up of qualitative targets is not mentioned here but in the progress reports one can find references to them. In the age of mass digitization qualitative targets seem as - or even more - important as quantitative ones.

Planning and monitoring based on hard data is a quite evident requirement in every controlling and management activity. Making the progress and results of digitization quantifiable is quite difficult as different measures can be defined. To support the member states' activities to collect statistically valid data on digitization and digital preservation, one of the key objectives of the European ENUMERATE project was "the creation, promotion and development of a statistically-valid open methodology for surveying the digitisation, use, preservation and associated costs of cultural heritage materials in Member States in order to develop an effective methodology for measuring digitisation”. (Poole, 2014)

There is a growing demand from the users' side for digitized content, which means exploitable business opportunities to profit-oriented companies. If private and public partners can harmonize their interests in the use of digitized content, synergies can be created that may result in better utilization of public moneys by involving extra human capacities, creativity or financial contribution. Ensuring "fair and balanced" cooperation is even a more difficult challenge. In the last reporting period European Commission has concluded that although the number of public private partnerships is growing only a few examples are available all over Europe (European Commission 2018).

The Structural Funds are important tools in the European Union's Regional Policies that function as a direct way of supporting member states' digitization policies. Generally, the poorer regions are eligible for more funding as the purpose of this tool is reduce regional disparities in the territories of the European Union. As most regions of the V4 countries fall into the most underdeveloped parts of the EU, the use of Structural Funds is a unique possibility for all of these states. When the analyzed reports were written, member states were in the middle of the 2014-2020 programming period. The fields and purposes in which the funds can be used depend on the programs prepared by the member states and accepted by the European Union.

Regarding pooling of digitization activities, most of the member states set up national aggregators that may have different functions that vary all over the countries. The term "competence center" is not defined in the recommendation and according to the progress reports most member states satisfy this recommendation by setting up aggregators; this can be cross-domain or domain specific depending on the sectors covered (e.g. libraries, museums, archives, audio-visual institutions). According to a recent survey, national aggregators' common missions are: 
1. Giving access to cultural heritage objects; 2 . Promoting resources and cultural heritage of their country; 3 . Setting up quality standards and creating high quality data and metadata (Truyen 2019). Further roles can be played that depend on the organization of digitization in the certain country.

The recommendation is obsolete in many ways, leading to the European Commission deciding to revise it with the active participation of member state experts and cultural heritage institutions (Fernandes 2019).

\section{Results}

In this section I will present the organization and funding of digitization in the Visegrád countries according to the information collected from the latest (2017) progress reports (European Commission 2017).

\section{Czech Republic}

Digitization of cultural heritage is an important part of the Czech cultural policy. This aim is presented in several upper and lower level policy documents.

1. State Culture Policy for 2015-2020 (with the view to 2025);

2. Culture Content Digitisation Strategy for 2013-2020;

3. Integrated Strategy of the Support of Culture to 2020;

4. Libraries Development Concept for 2011-2015 including digitization of libraries; and

5. Libraries Development Concept for 2017-2020 including digitization of libraries.

Digitization activities in the cultural field is financed by the Ministry of Culture that launched two national projects focusing on the digitization of: 1. rare documents, manuscripts and old prints; and 2. endangered material (monographs and periodicals) published after 1800. Both projects set up quantitative targets. Regarding rare documents, manuscripts and old prints, the project allows the digitization of 200 documents and approximately $60-80,000$ pages, while from post-1800 documents of about 550,000 pages can be digitized annually all over the country.

A central aggregator, Manuscriptorum, is responsible for the presentation of old documents collected from the participating institutions, while modern material is aggregated by Czech Digital Library (Lhoták 2016). According to the Eu- 
ropean recommendations, public-private partnerships (PPP) are launched with Google for the mass digitization of old prints.

European Union funding sources were also used for digitization in the Czech Republic. The National Digital Library (NDK) Project was co-financed from the European Union Integrated Operational Programme and from the budget of the Ministry of Culture. Since 2015 about six million pages have been digitized. All content is available via the Kramerius system, which also ensures the long-term preservation of endangered documents.

Endangered documents have priority in digitization in the Czech Republic. A central heritage management body, the Central Register of Cultural Heritage of the Czech Republic, is responsible for the selection of the listed cultural heritage. The register is managed by the National Heritage Institute.

Regarding public private partnerships, the Czech National Library could report a long-standing and successful cooperation with Google for the digitization of old printed books. The project started in 2011 and at the time of the progress report was still operating. Since 2014, the National Library of Czech Republic prepared the documents that are digitized and made available in the Google Digitization Centre. Altogether, 150,000 books have been published digitally as a result of this cooperation.

Concerning qualitative and quantitative targets, the biannual progress report mentions that under the national level of digitization "it is the interest of each memory institution to plan, budget, and routinely digitize at least those documents whose lifetime is limited and / or that their condition requires immediate rescue." On this lower level neither quantitative nor qualitative targets have been set. Regarding the Czech National Library as an example digitization is a continuously running process in which the institution can estimate the number of digitized items or pages.

A central Digitization Register is established to avoid unwanted duplications in the library fields. This mechanism saves financial resources and makes the progress of digitization more effective.

\section{Hungary}

The Hungarian progress report mentions several strategic documents that deal with digitization activities.

1. The Digital Nation Development Programme

2. Digital Well-being Programme

3. Digital Education Strategy

4. Public Collections Digitisation Strategy 
The documents are related to different levels. The Digital Nation Development Programme is a top-level government strategy that targets the digitalization of the citizen services in many different fields. The aim of this is to create a digital ecosystem that supports private companies and individuals in exploiting the possibilities of the digital change. The Digital Education Strategy and the Public Collections Digitisation Strategy are also parts of this program of which the latter defines the tasks of the cultural institutions for the 2017-2025 period. All institutional strategies and the strategies of the different domains should be derived from the Public Collections Digitisation Strategy.

The progress report mentions the European Digital Agenda as a top-level European framework that defines the expectations for every member state in the field of digitization. According to the report all of the abovementioned strategies are aiming to harmonize with this European initiative. The public collections are identified as authentic content providers of the knowledge-based society that have a unique role in providing other sectors with cultural content. The strategy is service-oriented and emphasizes content providing instead of preservation purposes.

The Public Collections Digitisation Strategy describes the framework of aggregation appointing aggregators in each sector. The National Széchényi Library is responsible for the aggregation of documents digitised in libraries, the Hungarian National Museum for museum content, the Hungarian National Archive for archival material and the Hungarian National Film Archive for movies and audiovisual material. The Forum Hungaricum Nonprofit Ltd., the successor of the former Hungarian National Digital Archives - MANDA (that functioned as a national aggregator in a previous era until 2016) is responsible for other content not covered by libraries, museums, archives and audiovisual institutions.

The present system - defined in the Public Collections Digitisation Strategy is building on former initiatives performed by institutions with a national scope. The progress report mentions one example. The National Centre for Museology and Museum Information which operates as a department of the Hungarian National Museum launched the MuseuMap aggregation service for materials digitized in Hungarian museums in 2014. This portal can function as a base for further development of museum aggregation activities. This was the main cause for appointing the Hungarian National Museum as a museum aggregator in Hungary. On the archival field it was also obvious that the Hungarian National Archive should function as national aggregator as organizationally it covers all of the former county archives. The National Inventory Project aims to create a joint portal for public collections material that ensures a common search interface both for end users and institutions. This portal will function as a top-level layer for aggregating content digitized in public collections. 
There are no real public-private partnerships launched in Hungary in the field of digitization of cultural heritage. One example is mentioned in the progress report in which a private company is involved in digitization activities. The company provides capacities and expertise for developing services based on cultural heritage objects. National funds are available for cultural heritage institutions that can be used for digitizing the objects from their collections by a private company. It profits twice from this cooperation, once when they are paid for digitization and once when the digitized content is sold to institutions or individuals.

Regarding qualitative targets, a group of experts has been set up called Public Collections Digitisation College, which colligates the efforts of the different sectors. This group is responsible for elaborating common guidelines that ensure the quality and interoperability of digitized resources all over the library, museum and archival fields. Aggregator institutions are also developing standards, vocabularies and guidelines for their own fields of interest. A good example for guidelines is the "White book" that is developed in the library field and contains metadata and quality requirements for ensuring interoperability and harmonization of services.

Concerning quantitative targets, the Public Collections Digitisation Strategy have set up a very ambitious goal intending to complete the digitization of 50\% of the documents compared to all documents to be digitized, and to make them accessible through the online search interface of the National Inventory Project. Another quantitative target was set up to support the realization of the Digital Education Strategy. The number of available digital curricula based on the material provided by public collections should increase by $40 \%$ until 2025 .

The European Union Structural Funds are used only for developing services. The implementation of the strategy is primarily financed by Hungarian governmental funds. An example that the progress report mentions is the National Library System project of the National Széchényi Library that functions as a complex development program for library digitization that contains the development of infrastructure, performing digitization, creating new services, elaborating standards and launching thematic portals.

\section{Poland}

The digitization of cultural heritage is part of several strategic documents in Poland. These strategies constitute the framework for all digitization activities in Poland.

1. Strategy for Responsible Development to 2020 - with the perspective to 2030 .

2. Strategy of Social Capital Development 2020 
3. Strategy of Digitisation of national archives resources for years 2017-2022

4. Programme of Digitisation of culture goods and collecting, storing and sharing digital objects in Poland 2009-2020

The first is the highest level strategy adopted in 2017 and contains the description of tasks in six respective areas (qualifying, defining, implementing strategic activities; digitization process; long-term storage of digital documents; creating a national repository system; providing access to digitized cultural material; cooperation between different sectors). The Social Capital Development Strategy constitutes a broader context of digitization defining activities related to digital culture in general. The national archives strategy is focusing on the network of state archives, while the last program contains the development of the national framework of digitization of cultural heritage.

Leading institutions were selected as competence centers for digitization of documents in each particular area. The national library functions as a competence center responsible for the digitization of library materials, the National Heritage Board for historical monuments, the National Digital Archives for archival documents, the National Institute of Museology and Collection Protection for museum objects and the National Film Archive - Audiovisual Institute for audiovisual materials.

The competence centers have been defined in a former Long-term Government Programme (Culture+ 2011-2015). They have been existing since 2016 and are responsible for various professional activities. These institutions store the copies of digitized documents and they have further different roles too, from organizing and realizing trainings to ensuring consultancy and professional guidance and updating standards in the field of digitization.

Digitization projects are partly financed from national sources via open calls and tenders and partly from the European Union Structural Funds. An example for the latter that the progress report mentioned was the Digital Poland Programme, priority axis II. E-administration and open government, specific objective 4. Increasing the availability and use of public sector information (Submeasure 2.3.2. Digital sharing of cultural resources) that costed more than 100 million EURs and was financed from European Union Regional Development Fund. Most of the digitization activities were financed from national sources in the different sectors. The cultural heritage institutions could apply for financial support. The report lists all successful projects of which we can mention some examples.

In Krakow's Closer to culture project intended to digitize the representative collections of one of the oldest and largest museums in Poland, the Polish Film Institute realized a project aimed to digitally reconstruct and digitize Polish films, documentaries and animations and provide access to all forms of distribution 
(cinema, television, Internet, mobile devices) and preserve Polish film heritage for future generations. The National Library of Poland launched a project for the digitization of and providing access to Polish national heritage from The National Library and Jagiellonian Library collections. The competence centers' budget was also defined by national sources.

According to the progress report, the Ministry of Culture and National Heritage of Poland has not received any information on public-private partnerships targeting digitization and or related services though - they think - such cooperation would be fruitful for the cultural heritage sector.

Quantitative targets haven't been set up on a national level, and the individual - competing - projects have to define the numbers of documents or pages that should be digitized within the project period. Qualitative objectives are defined by the Ministry of Culture and National Heritage. All beneficiaries should declare that the digitized material would be compliant with the cataloguing practices and standards defined in the different sectors (Catalogue of Practices and Standards of Digitisation of Library Facilities, Catalogue of Practices and Standards of Digitisation of Museum Facilities, Catalogue of Practices and Standards of Digitisation of Audiovisual Materials, Catalogue of Practices and Standards of Digitisation of Archive Materials, Catalogue of Practices and Standards of Digitisation of Historical Monuments).

The competence centers have a key role in the development of guidelines for the institutions. An example that can be mentioned here is the National Library of Poland that elaborated the Digitising Literature Handbook, which contains the quality requirements, recommendations and good practices that should be followed during mass digitization of written heritage. The same projects have been implemented in other sectors by the competence centers of the certain field.

\section{Slovakia}

Slovakia performs quite well among the Central and Eastern European countries in the mass digitization of cultural material. The use of EU structural funds is especially exemplary in that it made very complex and industrial-scale projects possible regarding the printed heritage (Kováčik 2017).

The Slovak Republic performs digitization of cultural material under the framework of the Development and Renewal of the National Infrastructure of Repository Institutions Priority Axis of the EU Structural Funds Informatisation of Society Operational Programme. The program aims to contribute to an inclusive information society and facilitate the development of a knowledge-based economy. The priority axis' objective on the one hand is to improve acquisition, 
processing, protecting and providing digitized cultural content, and on the other hand is to develop the infrastructure of the memory institutions functioning on a national level.

Three cross-domain infrastructural projects have been implemented that are dealing with the joint development of Slovak cultural institutions. These projects are focusing on the interoperability of information systems, long-term preservation of digitized content and developing tools for launching new services. The priority axis contains six domain specific digitization projects that are targeting the digitization of content of ALM (archives, libraries and museums) institutions. The aim of these projects is to create digital library, archive, gallery, museum, collection of monuments and audio-visual documents. The digitization projects also cover both the tangible and the intangible cultural heritage (e.g. folk dances, songs, customs etc.)

While implementation was financed by the European Union Structural Funds, the sustainability period is coordinated and funded from the budget of the Ministry of Culture of the Slovak Republic and cultural institutions. Every participating cultural institution has their own plan for digitization that ensures the sustainability of results achieved by using up European Union financial sources.

The Slovak progress report answered negatively to the question "have cultural institutions in your country entered into PPPs (including also partnerships with non-EU partners) for digitization or for facilitating the access to digital cultural heritage?"

According to the last progress report, quantitative targets have been set for each domain (e.g. Digital Library and Digital Archives set up a target of 2.52 million objects to digitize from the Slovak National Library and Slovak National Archives, the Slovak National Gallery and other Slovak galleries contributing to the Digital Gallery with 100,688 digitized objects.) All together, 3.09 million objects should have been digitized, which - at the end of the implementation period was exceeded by more than $30 \%$.

The quality of digital content and services is ensured by "manuals" elaborated for specific domains. These documents are based on European recommendations, contain requirements for resolution, metadata etc. and are obligatory for all projects funded from European sources. These manuals ensure the common standards for storage in central digital archives and for presentation on the national portal called Slovakiana.

The national cross domain aggregator, the National Cultural Center, was responsible for the realization of a national project that targeted the development of the Central Application Infrastructure and Registry which is a system for pre- 
senting every kind of digitized cultural material both on a national level and on Europeana. Using this system was a pre-condition for the approval of any digitization project in the country. The digitized items are registered centrally. The mechanism was developed to avoid unwanted duplications in the library field.

Digitization activities are hosted in specialized national digitization worksites for each domain. Printed library documents are digitized in the Digitisation Centre of the Slovak National Library, the paintings and statues in the Slovak National Gallery. This centralized approach simultaneously ensures the economies of scale and safeguards the quality of outputs

\section{Discussion}

The policy recommendations of the European Union allow for very wide possibilities for the member states for the implementation. In this paper I analyze how the different paragraphs related to organization and funding have been implemented in four Central and Eastern European countries (Czech Republic, Hungary, Poland and Slovakia) according to the progress reports that the national governments should submit in every second year to the European Commission. In this paragraph I compare the countries' systems in planning and monitoring, financing and capacity optimizing following the reports structure.

\section{Aims of Digitization}

What we can observe in the different strategic approaches appearing in the progress reports is that the aims of digitization vary from one country to another. While for example Hungary has a very strong orientation toward service delivery and generally digital well-being, the Czech Republic strongly focuses on old prints, rare documents and the long-term preservation of vulnerable cultural heritage materials. While in Poland responsible development and social capital appear in strategy documents, in Slovakia the effective use of Structural funds and high quantity of digitized material based on cross sectoral cooperation seem to be the main aspirations.

It seems that the common platform of V4 states regarding their historical background and cultural orientations do not mean that they would formulate the aims of digitization in the same way. 


\section{Planning and Monitoring}

Strategic planning and development in the field of digitization is in place in all four Visegrád countries. Every country has national strategy on digitization of cultural material, while Poland and Czech Republic reported having also domain specific initiatives for planning. It is only Slovakia that has a national funding program too, though according to the answers to open ended questions it is obvious that the extended use of European Union sources made financial planning necessary. In comparison to other European Union member states where only 19 out of 27 (the United Kingdom has not submitted the report for this period) reported having a national digitization strategy, the Visegrád countries seem very conscious regarding planning of professional activities (European Commission 2017). It is common in all four countries that the current system of digitization is heavily reliant on the national libraries, museums and archives which have a key role in organizing and performing digitization.

Quantitative targets are set up in every country though various approaches are followed in the different states. Hungary defined a target value in percentage in comparison with all content to be digitized. Slovakia defined target numbers of documents regarding each project of the different domains financed from European Union Structural Funds. In the Czech Republic and Poland centrally defined target values are not existing, and therefore the institutions are primarily responsible for planning the volume of digitization. There is no information about the effectiveness of the different approaches.

Qualitative targets are realized via manuals or standards in all countries. The main objective of setting such targets is to ensure semantic and technical interoperability between different levels of services (institutions, national cross-domain or domain-specific aggregators, contribution to Europeana). According to the reports, the following of standards and guidelines is a prerequisite for receiving financial support for the projects from national budgets.

In the Czech Republic and Slovakia there are national schemes for monitoring progress in the digitization of cultural material, while such a mechanism is lacking in Poland and Hungary. The former Czechoslovak states established national registers for monitoring purposes, while in other countries national institutions have to trace the progress of digitization. Avoiding unwanted duplication of digitized documents is a central argument for creating registries and following progress of digitization.

Participating in the data collections performed by the ENUMERATE network is an important contribution to a European-level monitoring mechanism. Three countries - Czech Republic, Hungary and Poland - reported that they encouraged and supported the participation of cultural institutions in the ENUMERATE 
surveys for the establishment of a European-level overview of digitization data. As far as Slovakia is concerned, it may have a clear correspondence with the low response rate to Enumerate questionnaires in the 2015-2017 period. In 2015 only three institutions responded, while in 2017 there was none that did (Nauta Heuvel 2015; Nauta - Heuvel - Teunisse 2017).

\section{Partnerships Between Cultural Institutions and Private Sector}

Only two countries reported any kind of cooperation between private and public partners. In the Czech Republic the national library collaborates with the Google Digitisation Centre while in Hungary a small company cooperates with libraries, museums and archives in order to produce and provide digitized content. The biggest challenge regarding public private partnerships is to find mutually advantageous ways for cooperation, because while the companies are interested in making profit, the cultural institutions - adjusted to their historic mission - insist on free access to information and cultural assets. On the other side, the huge technical capacities that big companies can ensure makes cooperation an attractive solution.

According to the consolidated report, the partnership launched by the Czech National Library is quite typical in other member states also: "Main reported PPPs are between national libraries and technology companies - most often involving multi-nationals such as Google and ProQuest (publisher) that are known to have a vested interest in text based content" (European Commission 2018). National libraries in Austria, Germany, Italy and the Netherlands are also involved in PPP cooperation with Google, and the Bibliothéque National de France with ProQuest.

\section{The Use of Structural Funds}

With the exception of Hungary all Visegrád countries reported that they used European Union Structural funds for financing digitization activities to various extents. This financial source is a unique possibility that can be used according to the predefined program that member states present to the European Union. In Hungary, the Structural Funds can be used for the development of services of institutions, but not for the digitization of analogue collections. Despite the negative answer in the Hungarian progress report, Hungary also used Structural Funds on a certain extent, but solely for developing services based on electronic sources and building technical capacities. 
When considering the entire European landscape, only two thirds of Member States reported making use of EU Structural and Investment Funds for the programming period 2014-2020. The ratio is much higher in Central and Eastern Europe. The preparations of the next programming period of 2021-2027 are underway which gives member states the possibility to make new considerations based on experiences in this period.

\section{Optimizing Capacities}

The optimization of capacities is a necessity for effective digitization and it can be conducted in several ways: by setting up national cross-domain or domain specific competence/digitization centers; by launching shared services or facilities at a national level or across borders; by starting other types of national or crossborder collaboration initiatives. Centralization efforts are quite typical in Central and Eastern Europe and according to the consolidated report all over Europe as well. All together 18 member states reported designated digitization and competence centers (European Commission 2018). While the recommendation clearly communicates competence centers (which emphasizes human skills and capacities), on the other hand it is obvious that digitization efforts are much more dependent on aggregators. The term "competence center" is present only in the Polish progress report of the analyzed four.

All Visegrád countries operate an aggregation mechanism, though the maturity of these systems is on a varied level. On one side of the scale is Hungary where a former system - in which one national aggregator was appointed - was recently changed into a complex, two-layered aggregation approach in which four domain specific aggregators collect digitized content and present on a common portal. The whole system is under development and exists only in plans. On the other side of the scale is Slovakia, which has a long-standing, well-functioning system with huge national institutions as domain-specific aggregators.

It is common in every Visegrád country that national institutions are responsible for pooling digitization capacities and efforts. These institutions are functioning as competence centers, as digitization centers and they are the main contributors to Europeana.

Regarding the organization and funding, several countries mention the priorities of digitization. The clear orientation toward services can be observed in Hungary, Slovakia and Poland. In Hungary the Public Collections Digitisation Strategy is explicitly service-oriented, giving priority to the digitization of content that caters immediate user needs. On the other side, the digital preservation of endangered material has the highest priority in the Czech Republic. 


\section{Conclusion}

The European Commission's recommendation on digitization and digital preservation and the progress reports that the European Union member states should submit every second year on the implementation of the recommendation let us make comparisons between digitization practices of European countries. The paper focused on the issues related to organization and funding that are key topics of the reports. The recommendation was issued eight years ago, in 2011. Despite the relatively long time passed since its publication, the key points seem still highly relevant and up to date as far as the organization and funding issues are concerned.

We could observe several similarities in the analysis of the latest progress reports. These similarities can be regarded as typical Central and Eastern European features in organizing digitization. The most striking similarities concerning organization are the following.

The strong intention toward pooling digitization capacities is very typical in Central and Eastern Europe. All analyzed countries are building on existing national institutions as aggregators and/or competence centers.

Regarding funding of digitization there are also common features. The extensive use of structural funds is especially important in these countries, which have a much lower economic power than their Western counterparts within the European Union. Perhaps this easily obtainable financial source makes these countries less ingenious in elaborating new funding mechanisms. Accordingly, we can find fewer examples for public private partnerships than in other European Union member states.

We could find differences as well. One example is the setting of quantitative targets which is very different in the Visegrád countries. On one side of the scale is Poland and the Czech Republic leaving the definition of targets to institutions, while on the other side is Hungary where very ambitious targets have been set centrally. Slovakia follows a third approach by setting numeric targets as indicators for European Union financed projects.

We presumed earlier that due to some similar cultural, political and economic background the countries' policymakers found analogous solutions that on the one hand fit to the European Commission's recommendation and on the other hand reflect the needs and potentials of the analyzed countries. We have not found reflections to the V4 countries' common platform and common background in the way they approach the digitization of the cultural heritage. We found that these processes are first and foremost directed by technological solutions. The countries followed different paths related to the aims of digitization of cultural heritage. 


\section{References}

European Commission. "Commission Decision of of 27 February 2006 Setting up a High Level Expert Group on Digital Libraries". Official Journal of the European Union, 49, 2006, 3233, 2019. Accessed August 30, 2019. https://eur-lex.europa.eu/legal-content/EN/TXT/ PDF/?uri=0J:L:2006:046:FULL\&from=EN.

European Commission. "Commission Recommendation of 24 August 2006 on the Digitisation and Online Accessibility of Cultural Material and Digital Preservation". Official Journal of the European Union, 236, 2006, 28-30, 2019. Accessed August 30. https://eur-lex. europa.eu/legal-content/EN/TXT/PDF/?uri=CELEX:32006H0585\&from=EN.

European Commission. "Council Conclusions of 20 November 2008 on the European Digital Library EUROPEANA”. Official Journal of the European Union, 319, 2008, 18-19, 2019. Letöltés dátuma August 30, 2019. forrás. https://eur-lex.europa.eu/legal-content/EN/TXT/ $\mathrm{PDF} /$ ?uri=CELEX:52008XG1213(04)\&from=EN.

European Commission. "Commission Recommendation of 27.10.2011 on the Digitisation and Online Accessibility of Cultural Material and Digital Preservation". Official Journal of the European Union, 283, 2011, 39-45, 2019. Accessed August 23, 2019. https://eurlex.europa.eu/legal-content/EN/TXT/PDF/?uri=CELEX:32011H0711\&from=EN.

European Commission. "Towards an Integrated Approach to Cultural Heritage for Europe". July 22, 2014. Brussels. Accessed August 23, 2019. https://ec.europa.eu/assets/eac/culture/ library/publications/2014-heritage-communication_en.pdf.

European Commission. "A Digital Single Market for Europe: Commission sets out 16 Initiatives to Make it Happen”. May 6, 2015. Brussels. Accessed August 23, 2019. https://europa.eu/ rapid/press-release_IP-15-4919_en.htm.

European Commission. "2017 National Reports on Digitisation, Online Accessibility and Digital Preservation”. October 20, 2017. Accessed August 26, 2019. https://ec.europa.eu/digitalsingle-market/en/news/2017-national-reports-digitisation-online-accessibility-anddigital-preservation.

European Commission. "Commission Decision of 7.3.2017 Setting up the Expert Group on Digital Cultural Heritage and Europeana”. March 7, 2017. Brussels. Accessed August 23, 2019. http://ec.europa.eu/information_society/newsroom/image/document/201742/commission_decision_dche_D19B28A2-BCEE-B2D6-81F1AA9FB3CE377C_47767.pdf.

European Commission. Cultural Heritage: Digitisation, Online Accessibility and Digital Preservation - Consolidated Progress Report on the implementation of Commission Recommendation (2011/711/EU) 2015-2017. Luxembourg: European Commisssion - Directorate General for Communications Networks, Content and Technology, 2018.

Fernandes, M. "Presentation on the Current State of Progress and Next Steps in the Process of Evaluating the Recommendation". Presentation at 6th Meeting of Expert Group on Digital Cultural Heritage and Europeana. European Commission. Luxembourg, 2019.

Heuvel, W.-G. v. Survey Report on Digitisation in European Cultural Heritage Institutions 2015. The Hague: Europeana, 2015. Accessed August 27, 2019. https://pro.europeana.eu/files/ Europeana_Professional/Projects/Project_list/ENUMERATE/deliverables/ev3-deliverabled1.2-europeana-version1.1-public.pdf.

Kováčik, J. “The National Project Digital Library and Digital Archives: Mass Digitisation of Printed Cultural Heritage Materials in Slovakia”. Alexandria, 27, no. 3, 163-174, 
2017. Accessed August 27, 2019. https://journals.sagepub.com/doi/full/10.1177/ 0955749018763720.

Lhoták, M. "The Czech Digital Library - Aggregation and Dissemination of Digital Content From the Czech Libraries". In Libraries V4 in the Decoy of Digital Age: Proceedings of the 6th Colloquium of Library and Information Experts of the V4+ Countries, pp. 345-351. Brno: Moravská zemská knihovna, 2016.

Poole, N. “MSEG ENUMERATE Workshop”. Luxembourg: European Commission, 2014. Accessed August 26, 2019. https://ec.europa.eu/digital-single-market/en/news/13th-meetingmseg.

Stokstad, S. "Norwegian National Policies for Digitalization in the LAM Sector -Imperative and Implementation". In Audunson, R., H. Andresen, C. Fagerlid, E. Henningsen, H-C. Hobohm, H. Jochumsen, H. Larsen, and T. Vold (eds), Libraries, Archives and Museums as Democratic Spaces in a Digital Age. Berlin: De Gruyter Saur, 2020.

Teunisse, G. J.-W.-S. Europeana DSI 2 - Access to Digital Resources of European Heritage Deliverable - D4.4 Report on ENUMERATE Core Survey 4. The Hague: Europeana, 2017. Accessed August 27, 2019. https://pro.europeana.eu/files/Europeana_Professional/Projects/ Project_list/ENUMERATE/deliverables/DSI-2_Deliverable\%20D4.4_Europeana_Report\% 20on\%20ENUMERATE\%20Core\%20Survey\%204.pdf.

Truyen, F. "Common Culture Capacity Building. Presentation at 5th Meeting of Expert Group on Digital Cultural Heritage and Europeana”. European Commission. Luxembourg: Letöltés dátuma, August 26, 2019. https://ec.europa.eu/digital-single-market/en/news/fifthmeeting-european-commissions-expert-group-digital-cultural-heritage-and-europeanadche. 
